\title{
A Comparative Study of the Metabolic and Skeletal Response of C57BL/6J and C57BL/6N Mice in a Diet-Induced Model of Type 2 Diabetes
}

\author{
Elizabeth Rendina-Ruedy, ${ }^{1}$ Kelsey D. Hembree, ${ }^{1}$ Angela Sasaki, ${ }^{1}$ McKale R. Davis, ${ }^{1}$ \\ Stan A. Lightfoot, ${ }^{2}$ Stephen L. Clarke, ${ }^{1}$ Edralin A. Lucas, ${ }^{1}$ and Brenda J. Smith ${ }^{1}$ \\ ${ }^{1}$ Department of Nutritional Sciences, Oklahoma State University, Stillwater, OK 74078, USA \\ ${ }^{2}$ Center for Cancer Prevention and Drug Development, University of Oklahoma Health Sciences Center, \\ Oklahoma City, OK 73104, USA \\ Correspondence should be addressed to Brenda J. Smith; bjsmith@okstate.edu
}

Received 4 December 2014; Revised 8 May 2015; Accepted 12 May 2015

Academic Editor: H. K. Biesalski

Copyright ( 2015 Elizabeth Rendina-Ruedy et al. This is an open access article distributed under the Creative Commons Attribution License, which permits unrestricted use, distribution, and reproduction in any medium, provided the original work is properly cited.

\begin{abstract}
Type 2 diabetes mellitus (T2DM) represents a complex clinical scenario of altered energy metabolism and increased fracture incidence. The C57BL/6 mouse model of diet-induced obesity has been used to study the mechanisms by which altered glucose homeostasis affects bone mass and quality, but genetic variations in substrains of C57BL/6 may have confounded data interpretation. This study investigated the long-term metabolic and skeletal consequences of two commonly used C57BL/6 substrains to a high fat (HF) diet. Male C57BL/6J, C57BL/6N, and the negative control strain, C3H/HeJ, mice were fed a control or HF diet for 24 wks. C57BL/6N mice on a HF diet demonstrated an increase in plasma insulin and blood glucose as early as 4 wk, whereas these responses were delayed in the $\mathrm{C} 57 \mathrm{BL} / 6 \mathrm{~J}$ mice. The $\mathrm{C} 57 \mathrm{BL} / 6 \mathrm{~N}$ mice exhibited more severe hepatic steatosis and inflammation. Only the $\mathrm{C} 57 \mathrm{BL} / 6 \mathrm{~N}$ mice lost significant trabecular bone in response to the high fat diet. The $\mathrm{C} 3 \mathrm{H} / \mathrm{HeJ}$ mice were protected from bone loss. The data show that C57BL/6J and C57BL/6N mice differ in their metabolic and skeletal response when fed a HF diet. These substrain differences should be considered when designing experiments and are likely to have implications on data interpretation and reproducibility.
\end{abstract}

\section{Introduction}

Increasing prevalence of type 2 diabetes mellitus (T2DM) has stimulated research focused on the pathogenesis and treatment of T2DM and its complications. Initial studies examining fracture as a possible complication of T2DM indicated that type 2 diabetics were not at risk of fracture based on bone mineral density (BMD), the clinical standard for screening [1-3]. However, data analyzed from clinical trials with fracture as an outcome variable instead of BMD revealed that both men and women with T2DM experience an increase in fracture (i.e., 1.5-3-fold) beginning 5-10 years after diagnosis [4-8]. Collectively, the clinical evidence indicates that, independent of BMD, type 2 diabetics are at increased risk of fracture that is exacerbated over time.
Rodent models have enabled investigators to study the molecular mechanisms involved in altering bone quality in T2DM [9]. One of the most commonly utilized models has been the C57BL/6 young growing mouse fed a diet high in total and saturated fat (HF), which exhibits an increase in adiposity, impaired glucose tolerance, and dyslipidemia, similar to prediabetes in humans [10-12]. C57BL/6 mice have been reported to exhibit decreased trabecular bone and either increased, decreased, or no change in cortical bone in response to long-term intake of a HF diet [13-17]. When alterations in bone microarchitecture occur, they are usually accompanied by impaired bone quality as evidenced by compromised biomechanical properties [15, 17-21]. Factors that may contribute to some of the discrepancies in the literature describing the skeletal response to a HF diet could 
be due to the composition of the diets, the age of the mice, the duration of the study, and, importantly, differences in the C57BL/6 mouse substrain's response (e.g., C57BL/6J or C57BL/6N) [13-16, 21].

A review of published reports revealed that studies utilizing different C57BL/6 substrains (e.g., C57BL/6J and $\mathrm{C} 57 \mathrm{BL} / 6 \mathrm{~N})$ are often treated interchangeably without mention of genetic variations that could have important implications on the results and their interpretation. For example, the $\mathrm{C} 57 \mathrm{BL} / 6 \mathrm{~J}$ mouse has a missense mutation in the gene encoding nicotinamide nucleotide transhydrogenase (Nnt) that alters RNA splicing and leads to the deletion of exons 711 [22-24]. When C57BL/6J mice are fed a high fat diet, they exhibit impaired glucose tolerance that appears to result from suppressed insulin secretion by pancreatic $\beta$-cells [25]. Thus, genetic differences in the $\mathrm{C} 57 \mathrm{BL} / 6 \mathrm{~J}$ mouse could contribute to some of the discrepancies in the literature in regard to metabolic and skeletal responses reported in the diet-induced obesity model of T2DM.

In contrast to the $\mathrm{C} 57 \mathrm{BL} / 6$ mouse, the $\mathrm{C} 3 \mathrm{H} / \mathrm{HeJ}$ mouse model has been used in mechanistic studies because of its blunted metabolic response to a high fat diet [26, 27]. $\mathrm{C} 3 \mathrm{H} / \mathrm{HeJ}$ mice have a nonfunctional toll-like receptor (TLR) 4 due to a point mutation in the toll-interleukin 1 receptor domain [26-28]. TLR-4 is expressed on bone cells (i.e., both the osteoblasts and osteoclasts) $[29,30]$. Our lab and others [31-34] have shown that TLR-4 ligands (e.g., lipopolysaccharide or LPS and saturated free fatty acids or sFFAs) as well as downstream inflammatory mediators have the potential to uncouple bone turnover. Because of interest in sFFAs and gut-derived LPS in the pathophysiology of T2DM and its complications, the $\mathrm{C} 3 \mathrm{H} / \mathrm{HeJ}$ strain has become an important research tool to examine the role of TLR-4 in these metabolic responses.

To date, a direct comparison of the long-term metabolic and skeletal responses of the C57BL/6J and C57BL/6N substrains to a HF diet has not been reported in the literature. If, as we hypothesized, the metabolic response to a HF diet in these two substrains differs due to genetic variations, this may alter the inflammatory response, hormones, and adipokines, subsequently affecting the bone. Such differences would be important relative to the interpretation of results and could assist investigators in selecting the most appropriate model. Furthermore, because of our laboratory's interest in TLR-4 and bone, in this study $\mathrm{C} 3 \mathrm{H} / \mathrm{HeJ}$ mice were used as a negative control for comparative purposes $[26,27]$.

\section{Methods}

2.1. Animal Care and Diets. Eight-week-old male mice, C57BL/6N from Charles River (Wilmington, MA) and $\mathrm{C} 57 \mathrm{BL} / 6 \mathrm{~J}$ and $\mathrm{C} 3 \mathrm{H} / \mathrm{HeJ}$ mice from Jackson Labs (Bar Harbor, $\mathrm{ME}$ ), were obtained ( $n=30 \mathrm{mice} / \mathrm{strain}$ ) for these studies. Animals were acclimated for 7 days and then randomly assigned to a control AIN-93M (10\% kcals from fat) or a HF (45\% kcals from fat; Harlan Teklad, TD.06415) diet for $24 \mathrm{wk}$. Body weight and food intake were recorded throughout the study. Total feed efficiency was calculated by determining the gain in body weight (mg) per energy unit consumed (kcal)
[35]. Venous tail blood was collected following a $6 \mathrm{hr}$ fast for evaluation of glucose and insulin at $4 \mathrm{wk}$ intervals. After $24 \mathrm{wk}$, mice were anesthetized (ketamine/xylazine cocktail 70 and $30 \mathrm{mg} / \mathrm{kg}$ body weight, resp.) as previously reported and whole body DXA (Lunar PIXI, GE Medical Systems, Madison, WI) scans were performed. Mice were exsanguinated via the carotid artery. An aliquot of blood was collected for total white blood cell (WBC) counts and the remainder processed for plasma in EDTA coated tubes and stored at $-80^{\circ} \mathrm{C}$. All procedures were approved by the Institutional Animal Care and Use Committee of Oklahoma State University.

2.2. Intraperitoneal Glucose Tolerance Test. One week prior to the end of the study (23rd wk), mice were fasted for 6 hrs and an intraperitoneal (IP) glucose tolerance test (IGTT) was performed. An IP glucose solution ( 2 g glucose $/ \mathrm{kg}$ bodyweight) was administered, followed by blood glucose monitoring at $15,30,60,90$, and $120 \mathrm{~min}$. Area under the curve (AUC) was determined by calculating the sum of rectangular area between each time point.

2.3. Analysis of Insulin, Adipokines, and Osteocalcin. Plasma insulin was assessed at $4 \mathrm{wk}$ intervals, whereas plasma leptin, adiponectin, and osteocalcin (OCN), both total OCN (Gla$\mathrm{OCN}$ ) and undercarboxylated OCN (Glu-OCN), were determined only at the final time point. All assays were performed using commercially available ELISA kits including insulin (Crystal Chem, Downers Grove, IL), leptin and adiponectin (EMD Millipore, Billerica, MA), and Gla-OCN and GluOCN (Clontech Takara Bio, Mountain View, CA), following the manufacturer's protocol. Gla-OCN is reported as an indicator of bone turnover and given the importance of the carboxylation status of OCN relative to total OCN on glucose metabolism [20], the ratio of [Glu-OCN]/[Gla-OCN] was calculated to provide insight into the relationship between the skeletal and metabolic response to treatment.

2.4. Body Composition and Bone Densitometry. Whole body DXA scans were performed to determine body composition, bone mineral area (BMA), content (BMC), and BMD. All scans were analyzed using PIXImus Series Software version 1.4x (GE Lunar PIXI, Madison, WI).

2.5. Microcomputerized Tomography (Micro-CT). Micro-CT (micro-CT 40, SCANCO Medical, Switzerland) was used to evaluate bone microarchitecture at the proximal tibia metaphysis, tibia middiaphysis, and 4th lumbar vertebral body. Analysis of trabecular bone was performed at the proximal tibia metaphysis on high resolution scans (2048 $\times 2048$ pixels) and the volume of interest (VOI) included $750 \mu \mathrm{m}$ of secondary spongiosa. The VOI was analyzed using a threshold of 300, a sigma of 0.7 , and support of 1.0. Trabecular bone of the vertebra was assessed on images $80 \mu \mathrm{m}$ from the dorsal and caudal growth plates at medium resolution $(1024 \times 1024$ pixels $)$ and included only secondary spongiosa. Images generated from the scans of the vertebrae were analyzed at a threshold of 340 and a sigma and support of 1.2 and 2.0, respectively. Trabecular parameters evaluated included trabecular bone volume expressed as a 
percentage of total volume (BV/TV), trabecular number (Tb.N.), trabecular thickness (Tb.Th.), trabecular separation (Tb.Sp.) connectivity density (ConnDens), and structural model index (SMI).

Cortical bone was evaluated by analyzing a $120 \mu \mathrm{m} \mathrm{sec}-$ tion at the mid-diaphysis of the tibia. Assessment of cortical bone parameters included cortical porosity, thickness, area, and medullary area of the tibial middiaphysis. The acquired images were analyzed at a threshold of 300 , a sigma of 0.7 , and support of 1.0.

2.6. Analysis of Biomechanical Properties of the Tibia. Tibiae were cleaned of soft-adhering tissue and stored in phosphate buffered saline (PBS) at $4^{\circ} \mathrm{C}$ until analyses were performed. Reference point indentation (RPI) was applied laterally at the tibia-fibula junction using a BioDent (Active Life Scientific, Inc., Santa Barbara, CA), and the first cycle indentation distance and touchdown distance were recorded. Each tibia was subjected to a testing protocol of $2 \mathrm{~N}$ force, $2 \mathrm{~Hz}$, and 10 cycles.

2.7. Histology of the Liver. Fixed ( $10 \%$ neutral buffered formalin) liver samples were processed and sectioned $(5 \mu \mathrm{m})$ for staining with hematoxylin and eosin to assess histological changes associated with nonalcoholic fatty liver disease (NAFLD) that occurs in obesity and/or diabetes. Steatosis and fibrosis were scored on a scale from 0 to 4 , with 0 indicating the absence of hepatic lipid droplets or fibrosis, whereas 4 indicated pronounced steatosis or fibrosis. Lobular and portal inflammation was scored using a range of $0-3$, with 0 indicating the absence of macrophage infiltration and 3 corresponding to severe inflammation. Balloon degeneration was scored using a $0-2$ system, with 0 defined as the lack of degeneration and 2 indicating modest presence of parenchymal cell death. All scoring was performed by the study pathologist who was blinded to treatments.

2.8. RNA Isolation and Gene Expression Analysis. Total RNA was isolated from the liver and bone marrow using TriZol Reagent (Invitrogen, Grand Island, NY) as previously described [36, 37]. cDNA was synthesized following a standardized laboratory protocol and qPCR was performed using SYBR green chemistry (7900HT Fast Real-Time, Applied Biosystems, Foster City, CA). Hepatic genes of interest included fatty acid synthase (Fasn), sterol regulatory elementbinding protein $(S r e b p 1 c)$, glucose transporter 2 or solute carrier family (Slc2a2), peroxisome proliferative-activator $\alpha$ (Ppara), and glutathione peroxidase (Gpxl) and in the bone marrow Fasn, Ppara, and Gpx1 (Table S1 available online at http://dx.doi.org/10.1155/2015/758080). All qPCR results were evaluated by the comparative cycle number at threshold $\left(\mathrm{C}_{\mathrm{Q}}\right)$ method (User Manual \#2, Applied Biosystems) using peptidylprolyl isomerase $\mathrm{B}$ or cyclophilin $\mathrm{B}($ Ppib) as the invariant control.

2.9. Statistical Analysis. Statistical analyses were performed using Statistical Analysis Software version 9.3 (SAS Institute, NC). The primary objective was to determine the difference in response to a $\mathrm{HF}$ diet of a given strain and, therefore,

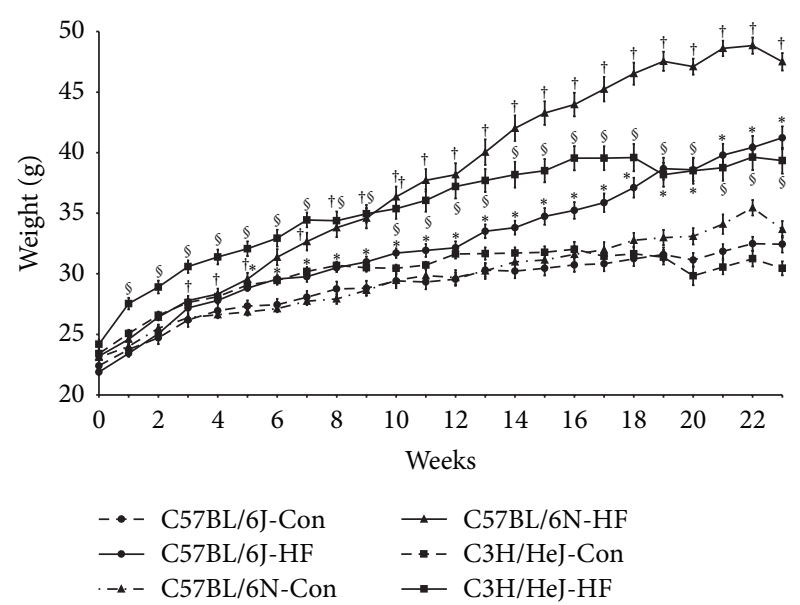

Figure 1: Body weights of C57BL/6J, C57BL/6N, and C3H/HeJ mice fed a control (Con; AIN-93M) or a high fat diet (HF; $45 \% \mathrm{kcal}$ from fat) were recorded weekly. Data is presented as the mean $\pm \mathrm{SE}, n=15$ mice in each group. Symbols, * for C57BL/6J, $\uparrow$ for C57BL/6N, or $\$$ for $\mathrm{C} 3 \mathrm{H} / \mathrm{HeJ}$, indicate significant differences $(P<0.05)$ of dietary treatment within a given mouse strain.

Student's paired $t$-test was used unless stated otherwise. However, to further assess differences in the responsiveness between the two C57BL/6 substrains, if a statistical difference $(P<0.05)$ was observed for a given parameter between Con and HF within a given strain, the magnitude of response (i.e., percent change of HF compared to Con) was compared between strains using one-way ANOVA. When the $F$ value was $<0.05$, post hoc analyses were performed with Fischer's least square means separation test. Chi-squared tests were used for histological scoring of liver specimens. All data are presented as mean \pm standard error (SE) and a $P<0.05$ was considered statistically significant.

\section{Results}

3.1. Body and Fat Pad Weight, Body Composition, and Feed Efficiency. At baseline, body weight between strains differed $(\mathrm{C} 3 \mathrm{H} / \mathrm{HeJ}>\mathrm{C} 57 \mathrm{BL} / 6 \mathrm{~N}>\mathrm{C} 57 \mathrm{BL} / 6 \mathrm{~J})$; however, no differences existed within a given strain between the two dietary treatment groups (i.e., Con versus HF; data not shown). After $5 \mathrm{wk}$ on the $\mathrm{HF}$ diet, the C57BL/6J exhibited a significant increase in body weight compared to the C57BL/6J Con, whereas the $\mathrm{C} 57 \mathrm{BL} / 6 \mathrm{~N}$ on the HF diet had a higher $(P<$ 0.05 ) body weight after only 3 wk (Figure 1 ). The $\mathrm{C} 3 \mathrm{H} / \mathrm{HeJ}$ mice on the HF diet also exhibited a more rapid increase in body weight after only 1 wk compared to their respective controls (Figure 1). Analysis of body composition revealed the increase in body weight was due to a significant increase in both lean and fat mass for the two C57BL/6 substrains as well as the $\mathrm{C} 3 \mathrm{H} / \mathrm{HeJ}$ mice (Table 1). The amount of food consumed was less for the mice on the HF diet in each strain (Table 1). However, on a kcal basis the C57BL/6N mice on the $\mathrm{HF}$ diet consumed $+2.1 \mathrm{kcal} /$ day and the $\mathrm{C} 57 \mathrm{BL} / 6 \mathrm{~J}$ and $\mathrm{C} 3 \mathrm{H} / \mathrm{HeJ}$ on the $\mathrm{HF}$ diet consumed $+1.2 \mathrm{kcal} /$ day compared to their respective controls (data not shown). Overall, feed 


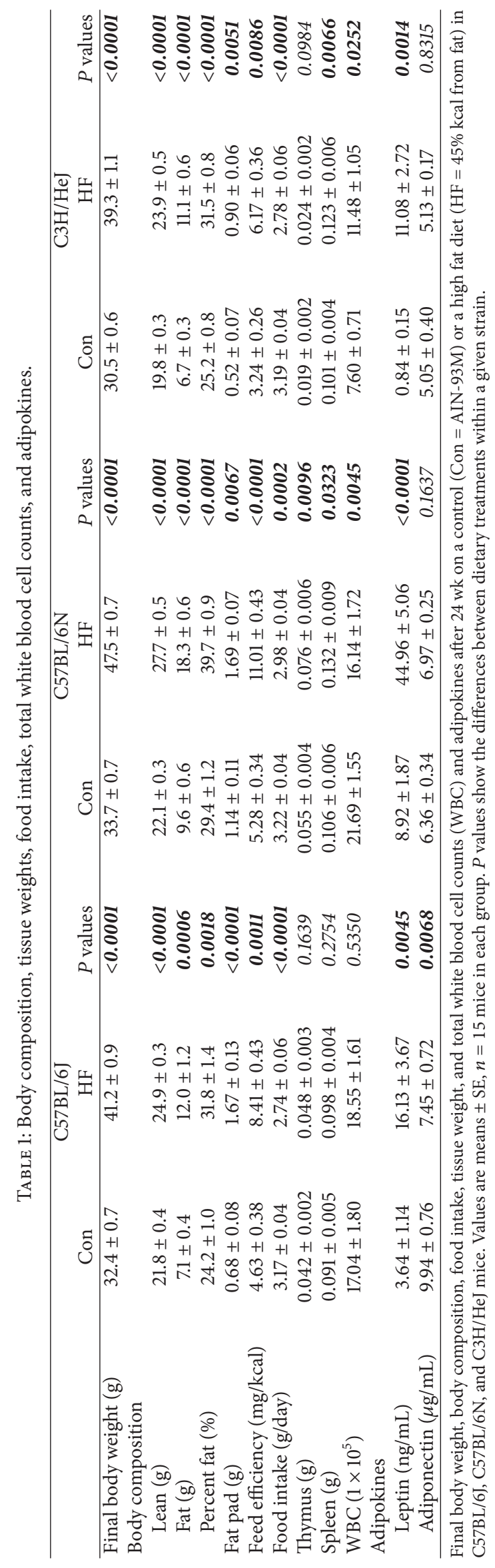




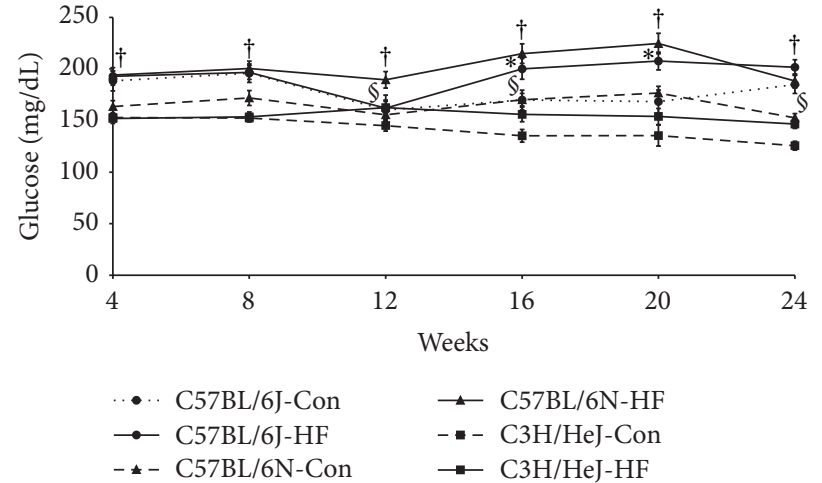

(a)

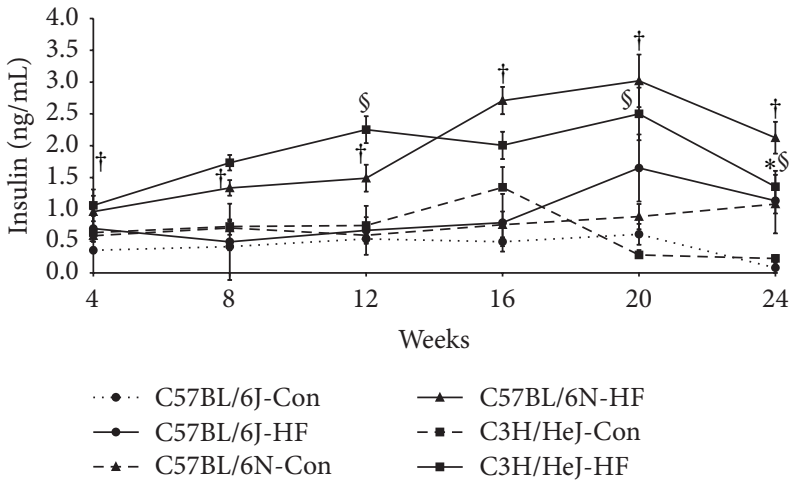

(b)

Figure 2: Blood glucose (a) and plasma insulin (b) were determined at 4 wk intervals in mice from each of the three strains fed a control (Con; AIN-93M) or a high fat diet (HF; 45\% kcal from fat). Symbols, $*$ for C57BL/6J, $\uparrow$ for C57BL/6N, or $\$$ for C3H/HeJ, indicate significant differences $(P<0.05)$ of dietary treatment for a given mouse strain.

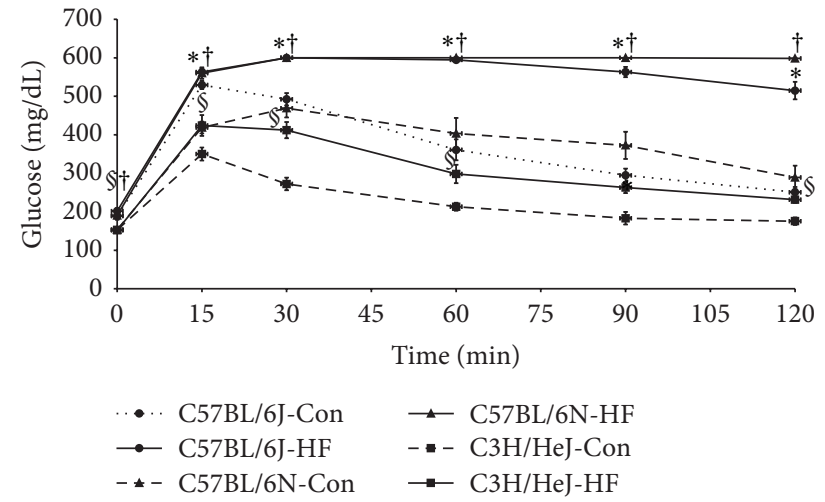

(a)

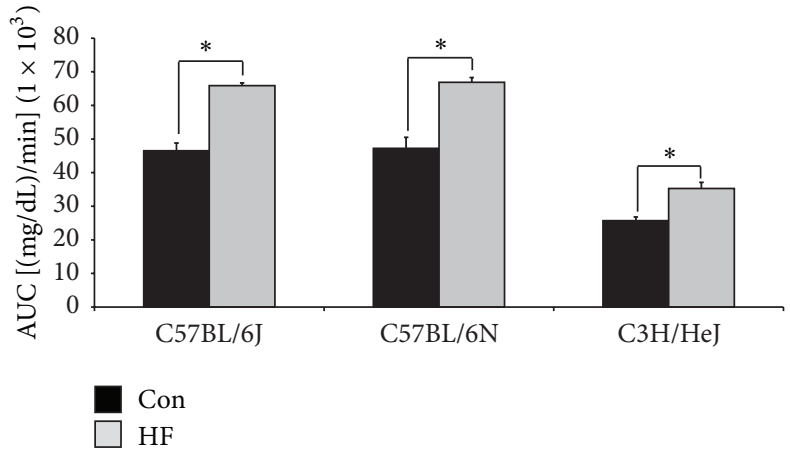

(b)

FIGURE 3: Glucose tolerance test results following $24 \mathrm{wk}$ on control or high fat diet. One week prior to the end of the study, an intraperitoneal glucose tolerance test was administered $(2 \mathrm{~g}$ glucose/ $\mathrm{kg}$ body weight) in the C57BL/6J, C57BL/6N, and C3H/HeJ mice fed a control (Con; AIN-93M) or a high fat diet (HF; 45\% kcal from fat). (a) Tail blood was collected following 15, 30, 60, 90, and 120 min following glucose injection and symbols, $*$ for C57BL/6J, $\uparrow$ for C57BL/6N, or $\$ \mathrm{C} 3 \mathrm{H} / \mathrm{HeJ}$, indicate significant differences $(P<0.05)$ of dietary treatment for a given mouse strain. (b) Area under the curve (AUC) was calculated for the IGTT and symbol, $*$, represents a significant difference $(P<0.05)$ between dietary treatments for a given strain.

efficiency was higher in the C57BL/6N mice than in the C57BL/6J mice on the HF diet (Table 1), further demonstrating the differences in metabolic responsiveness between these two substrains.

3.2. Tissue Weights and White Blood Cells. After $24 \mathrm{wk}$ on a $\mathrm{HF}$ diet the C57BL/6N mice exhibited splenomegaly, thymic hypertrophy, and decreased WBC, but the C57BL/6J mice failed to demonstrate these immunological changes (Table 1). $\mathrm{C} 3 \mathrm{H} / \mathrm{HeJ}$ mice had a similar response to the HF diet in terms of tissue weights (i.e., spleen and thymus) and total WBCs compared to the C57BL/6N mice (Table 1).

\subsection{Blood Glucose, Plasma Insulin, and Glucose Tolerance} Test. C57BL/6N mice on the HF diet were the only strain that had elevated fasting blood glucose (Figure 2(a)) and plasma insulin (Figure 2(b)) after 4, 8, 12, 16, 20, and 24 wk of treatment compared to their Con counterparts. The C57BL/6J substrain on the HF diet was hyperglycemic at 16 and $20 \mathrm{wk}$ (Figure 2(a)) and hyperinsulinemic at $24 \mathrm{wk}$ (Figure 2(b)). Importantly, neither substrain achieved a fasting blood glucose consistent with frank diabetes (i.e., $>250 \mathrm{mg} / \mathrm{dL}$ ) that is associated with polyuria and polydipsia [38]. Similar to the $\mathrm{C} 57 \mathrm{BL} / 6 \mathrm{~J}$ mice, the $\mathrm{C} 3 \mathrm{H} / \mathrm{HeJ}$ strain on the $\mathrm{HF}$ diet exhibited delayed-onset of hyperglycemia (Figure 2(a)), while their plasma insulin was increased at 12, 20, and $24 \mathrm{wk}$ (Figure 2(b)).

At the end of the study, IGTT showed that the C57BL/6J and $\mathrm{C} 57 \mathrm{BL} / 6 \mathrm{~N}$ as well as the $\mathrm{C} 3 \mathrm{H} / \mathrm{HeJ}$ mice on the $\mathrm{HF}$ diet exhibited impaired glucose intolerance (Figures 3(a) and $3(b))$. The percent change in AUC to the HF diet demonstrated that the magnitude of response of the two C57BL/6 substrains was similar (data not shown). The $\mathrm{C} 3 \mathrm{H} / \mathrm{HeJ}$ mice also exhibited impaired glucose intolerance after $24 \mathrm{wk}$ on a 


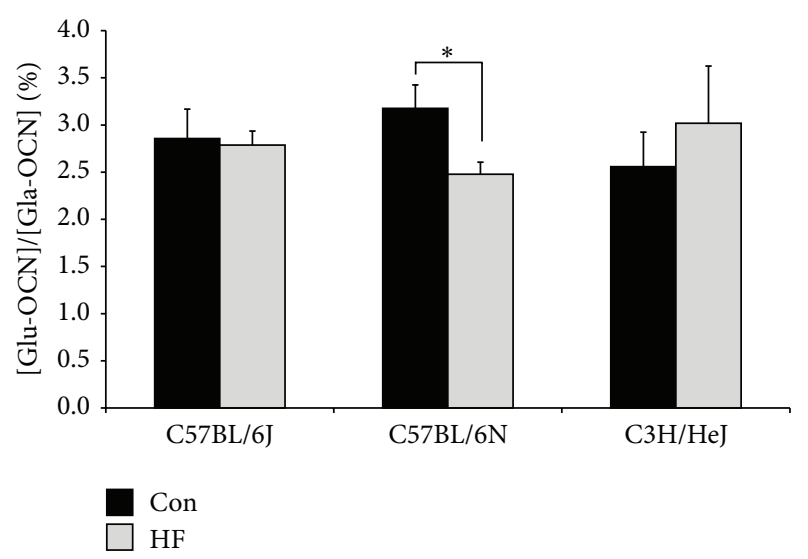

FIGURE 4: Plasma osteocalcin (OCN) expressed as percent of undercarboxylated Glu-OCN per total Gla-OCN in C57BL/6J, C57BL/6N, and $\mathrm{C} 3 \mathrm{H} / \mathrm{HeJ}$ mice on a control (Con; AIN-93M) or a high fat diet (HF; 45\% kcal from fat) after $24 \mathrm{wk}$. Symbol, $*$, represents a significant difference $(P<0.05)$ between dietary treatments for a given strain.

HF diet (Figure 3). It should be noted that, despite elevated AUC, the $\mathrm{C} 3 \mathrm{H} / \mathrm{HeJ}$ mice on the HF diet maintained the ability to restore blood glucose by the final IGTT time point.

3.4. Plasma Adipokines and Osteocalcin. Both the C57BL/6J and $\mathrm{C} 57 \mathrm{BL} / 6 \mathrm{~N}$ substrains had elevated plasma leptin after 24 wk on a HF diet (Table 1), but there was no significant difference in the magnitude of the response between the two substrains. Similarly, the $\mathrm{C} 3 \mathrm{H} / \mathrm{HeJ}$ mice on the HF diet also had higher plasma leptin (Table 1). Interestingly, at $24 \mathrm{wk}$ the C57BL/6J mice, but not the C57BL/6N substrain, exhibited a decrease in plasma adiponectin in response to a HF diet (Table 1).

After $24 \mathrm{wk}$ on a HF diet, there were no differences in Gla-OCN as an indicator of bone turnover due to diet in the $\mathrm{C} 57 \mathrm{BL} / 6$ substrains or $\mathrm{C} 3 \mathrm{H} / \mathrm{HeJ}$ mice (data not show). The carboxylation status of OCN (i.e., Glu/Gla-OCN ratio), which has been shown to influence insulin sensitivity and systemic energy metabolism, was reduced only in the C57BL/6N mice after $24 \mathrm{wk}$ on a HF diet (Figure 4).

3.5. Histological Evaluation of Hepatic Tissue. Representative micrographs of liver sections from each group show that the C57BL/6J and C57BL/6N strains as well as the $\mathrm{C} 3 \mathrm{H} / \mathrm{HeJ}$ strain experienced some degree of hepatic steatosis in response to the HF diet (Figure 5). The C57BL/6N mice on the HF diet had a significantly higher lobular and portal inflammation mean score compared to the Con (Table 2). Although the C57BL/6J mice on the HF diet had more lobular inflammation than their respective controls $(P=$ 0.0038 ), the frequency of the inflammatory response was markedly lower in this substrain compared to the C57BL/6N (i.e., lobular inflammation in $92 \% \mathrm{C} 57 \mathrm{BL} / 6 \mathrm{~N}$ versus $54 \%$ C57BL/6 and portal inflammation in $77 \% \mathrm{C} 57 \mathrm{BL} / 6 \mathrm{~N}$ versus $23 \%$ C57BL/6J) (Table 2). While none of the C57BL/6J mice on the HF diet exhibited liver fibrosis, $23 \%$ of the treated
C57BL/6N mice had fibrotic changes (Table 2). Balloon degeneration was also more severe in the $\mathrm{C} 57 \mathrm{BL} / 6 \mathrm{~N}$ mice on the HF diet compared to the C57BL/6J (Table 2). Despite a lack of lobular and portal inflammation and fibrosis in the $\mathrm{C} 3 \mathrm{H} / \mathrm{HeJ}$ mice, balloon degeneration was severe in this strain (Table 2).

3.6. Whole Body Bone Densitometry. Both the C57BL/6J and C57BL/6N mice demonstrated a decrease in whole body $\mathrm{BMC}$ and BMA, but no change in whole body BMD in response to the HF diet after $24 \mathrm{wk}$ (Table 3). When BMD was expressed relative to body weight, differences due to diet were observed suggesting that the bone density did not increase relative to the increase in body weight (Table 3).

\subsection{Microarchitectural Changes in Trabecular and Cortical} Bone. Micro-CT analyses of the lumbar vertebra revealed significant loss of trabecular bone or BV/TV with the HF diet in C57BL/6N, while the skeletal response of the C57BL/6J mice did not reach the level of statistical significance $(P<$ 0.0579) (Figure 6(a)). As expected, the $\mathrm{C} 3 \mathrm{H} / \mathrm{HeJ}$ mice were protected from vertebral bone loss (Figure 6) or nonmorphometric parameters with HF diet (Table 3). Both the C57BL/6J and C57BL/6N mice on the HF diet had a higher SMI indicative of a weaker, more rod-like trabecular bone in the vertebra (Table 3).

In contrast to the vertebra, no changes were observed in trabecular or cortical parameters analyzed at the proximal tibial metaphysis or the tibial middiaphysis in the C57BL/6J or the $\mathrm{C} 57 \mathrm{BL} / 6 \mathrm{~N}$ mice. The $\mathrm{C} 3 \mathrm{H} / \mathrm{HeJ}$ mice failed to demonstrate alterations in trabecular bone of the proximal tibia but did exhibit an increase in the medullary area at the middiaphysis (Table 3).

3.8. Changes in Biomechanical Properties of the Tibia. Based on reference point indentation testing on cortical bone at the tibia-fibula junction, no changes were observed in first cycle indentation distance or touchdown distance in any strain following $24 \mathrm{wk}$ on a HF diet when compared to their respective Con (Table 3 ).

\subsection{Characterization of Genes Involved in Energy Metabolism} and Inflammation from the Liver and Bone Marrow. Determination of genes involved in hepatic metabolism and inflammation revealed that the C57BL/6N mice on the HF diet had altered metabolic processes, including the upregulation of glucose uptake (Slc2a2), triglyceride storage (Fasn and Srebp1c) and adipogenesis (Ppara), as well as antioxidant capacity (GpxI) (Table 4). Interestingly, none of these alterations in gene expression were observed in the $\mathrm{C} 57 \mathrm{BL} / 6 \mathrm{~J}$ mice after $24 \mathrm{wk}$ on the HF diet.

To determine the degree to which oxidative stress and adipogenesis contributed to bone loss with the HF diet model, Gpxl and Pparg mRNA abundance was determined in the bone marrow. Similar to the hepatic tissue, the abundance of Gpx1 mRNA was increased in the C57BL/6N mice on the HF diet, suggesting an increase in antioxidant capacity (Table 4). In contrast, the C57BL/6J mice on the HF diet 
TABle 2: Pathological scoring of hepatic tissue after 24 wk on a control or high fat diet.

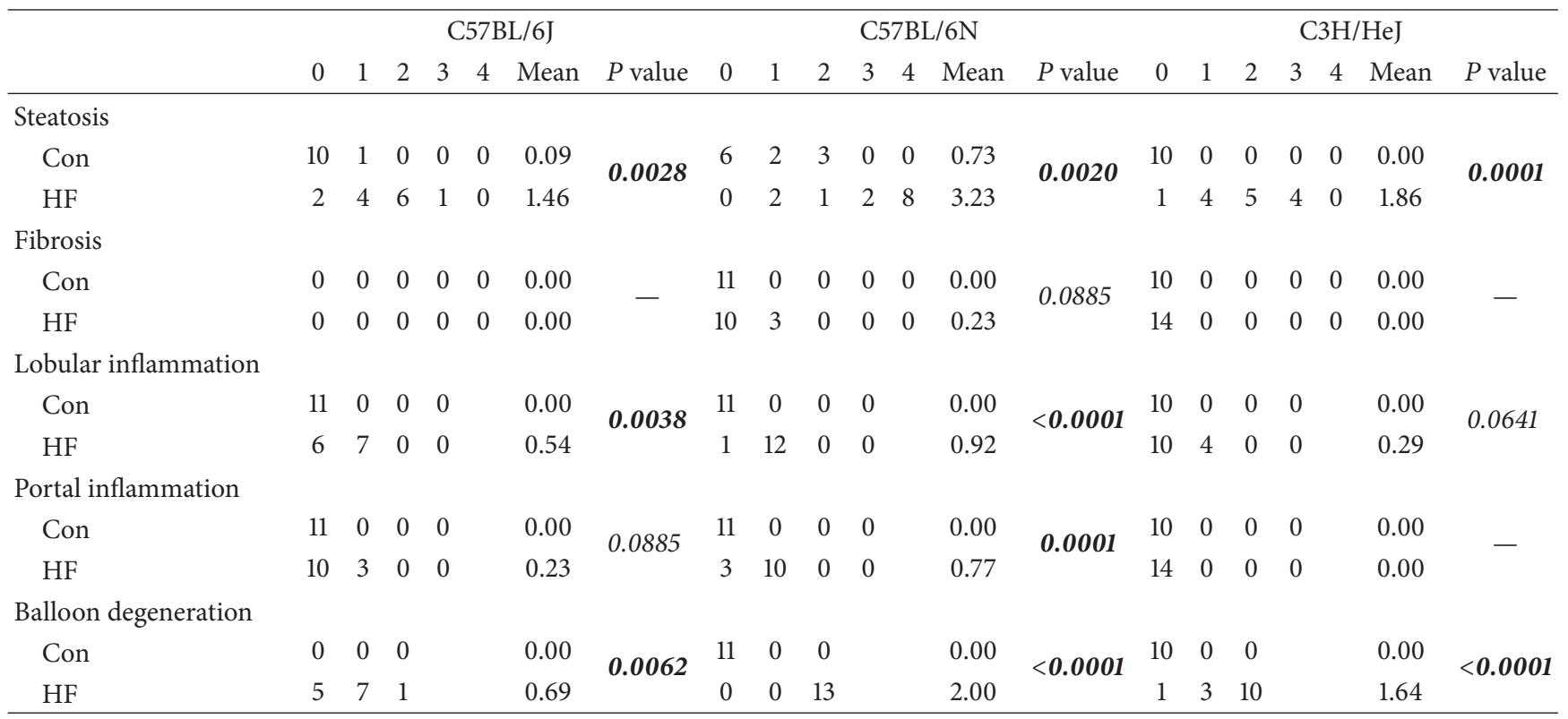

Frequency of steatosis $(0-4)$, lobular and portal inflammation ( $0-3)$, fibrosis $(0-4)$, and balloon degeneration $(0-2)$, along with mean scores and $P$ values for control versus high fat diet within a given strain based on Chi-squared statistical analyses.
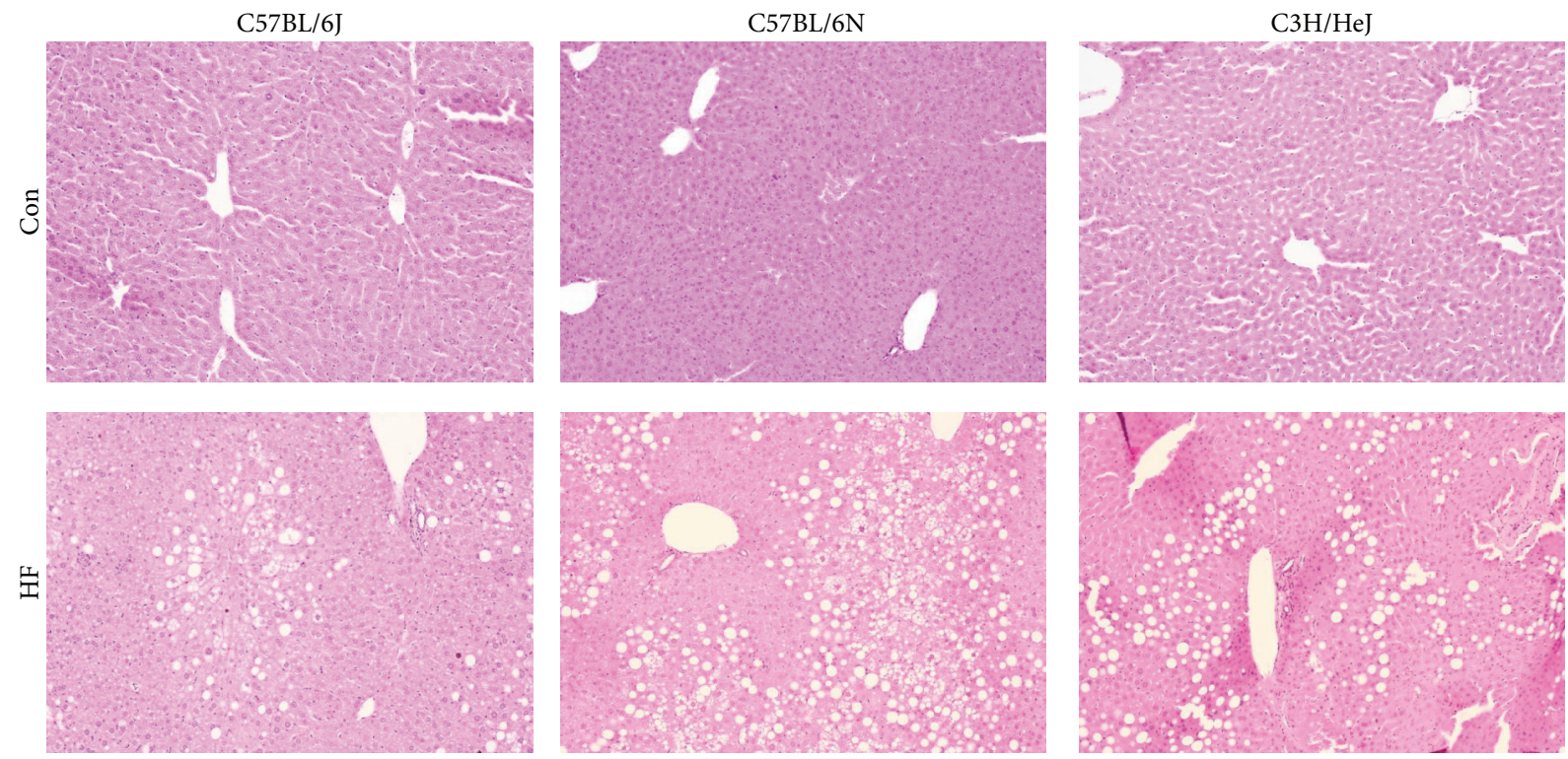

FiguRE 5: Representative micrographs of liver histology sections stained with hematoxylin and eosin from C57BL/6J, C57BL/6N, and $\mathrm{C} 3 \mathrm{H} / \mathrm{HeJ}$ mice following $24 \mathrm{wk}$ on a control (Con; AIN-93M) or a high fat diet (HF; $45 \% \mathrm{kcal}$ from fat). Representative images were photographed and are presented at a 10x magnification.

demonstrated a decrease in the relative abundance of Gpx1 (Table 4). Additionally, no alterations were observed in the transcriptional regulator of adipogenesis, Pparg, in any strain after $24 \mathrm{wk}$ (Table 4$)$.

\section{Conclusions}

The findings of this study show that the C57BL/6J and the C57BL/6N mouse differ in their metabolic response to a
HF diet over a 24 wk study period. Discrepancies in the metabolic response between the two strains may be attributed in part to the missense mutation (M35T) in exon 1 and a multiexon deletion of $\mathrm{N} n t$ in the C57BL/6J mice $[39,40]$. This mutation in $N n t$ has been reported to uncouple $\beta$-cell mitochondrial metabolism leading to less ATP production in pancreatic islets, enhanced $\mathrm{K}_{\mathrm{ATP}}$ channel activity, and, consequently, impaired glucose-stimulated insulin secretion $[23,39,41]$. Only fasting insulin was assessed in the current 


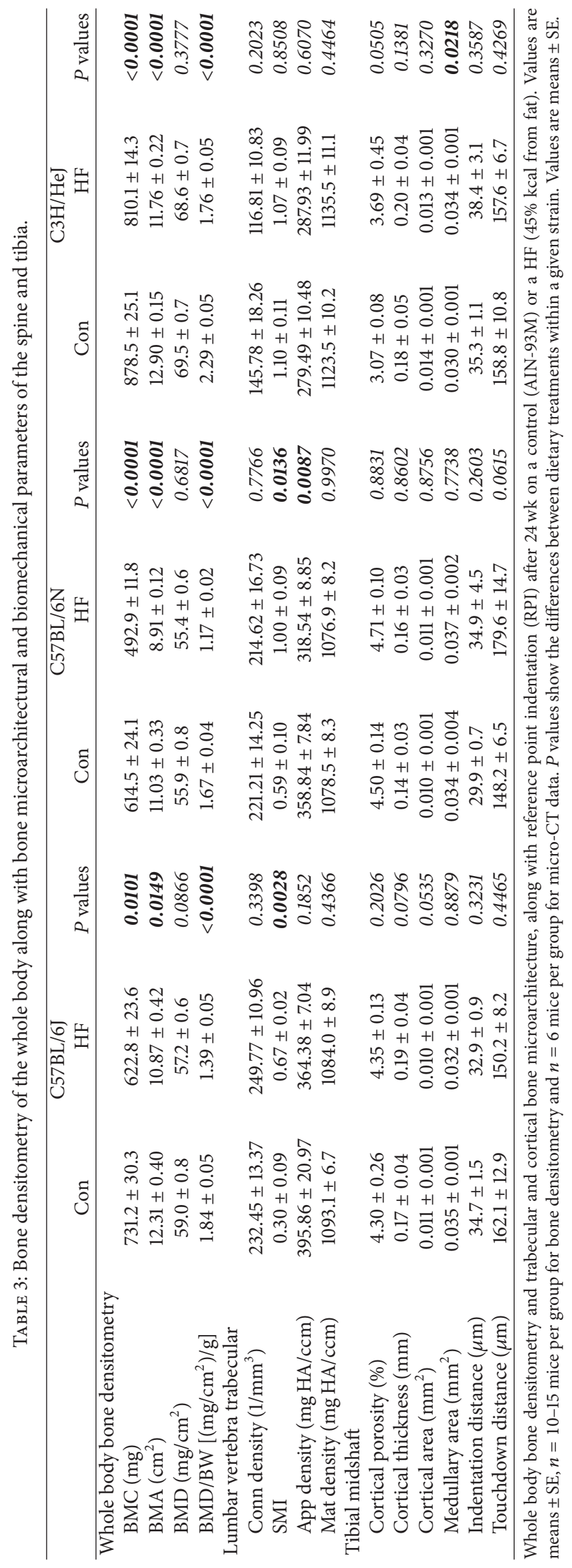




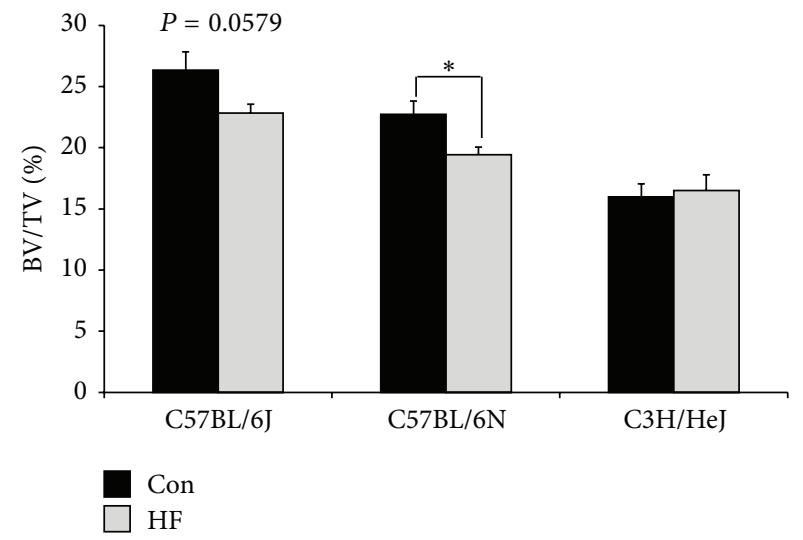

(a)

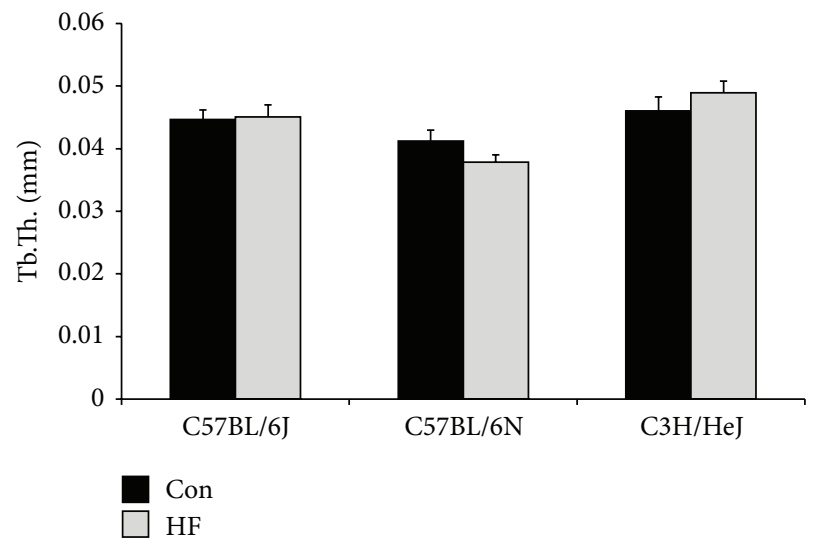

(c)

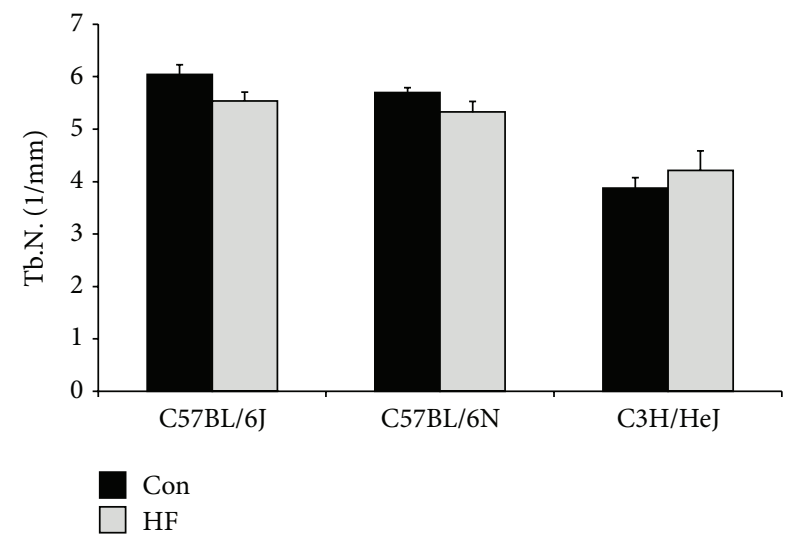

(b)

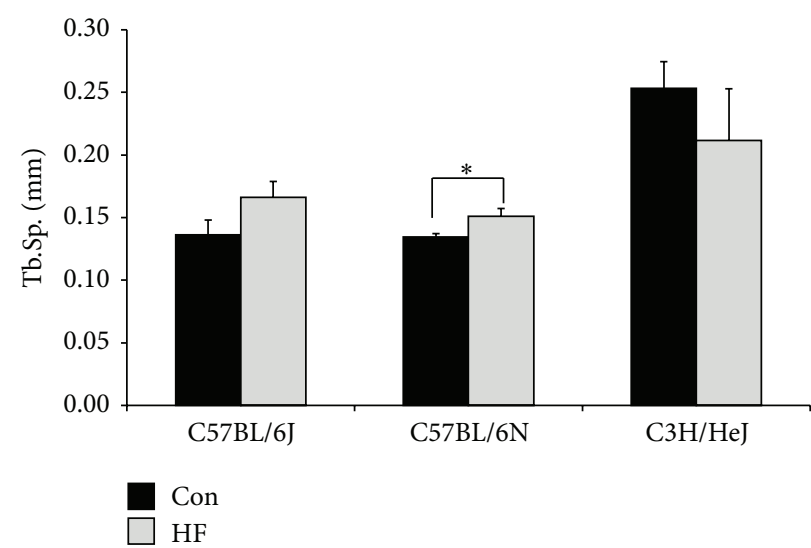

(d)

FIGURE 6: Micro-CT analyses of trabecular bone in the lumbar vertebra (L4) in C57BL/6J, C57BL/6N, and C3H/HeJ mice on a control (Con; AIN-93M) or a high fat diet (HF; 45\% kcal from fat) for $24 \mathrm{wk}$. Parameters include (a) bone volume/total volume (BV/TV), (b) trabecular number (Tb.N.), (c) trabecular thickness (Tb.Th.), and (d) trabecular separation (Tb.Sp.). Symbol, $*$, represents a significant difference $(P<$ $0.05)$ between dietary treatments for a given strain.

TABLE 4: Relative fold change of gene expression in the liver and bone marrow in mice fed a high fat diet compared to the control diet.

\begin{tabular}{|c|c|c|c|c|c|c|}
\hline & \multicolumn{2}{|c|}{ C57BL/6J } & \multicolumn{2}{|c|}{$\mathrm{C} 57 \mathrm{BL} / 6 \mathrm{~N}$} & \multicolumn{2}{|c|}{$\mathrm{C} 3 \mathrm{H} / \mathrm{HeJ}$} \\
\hline & $\mathrm{HF}$ & $P$ value & $\mathrm{HF}$ & $P$ value & $\mathrm{HF}$ & $P$ value \\
\hline \multicolumn{7}{|l|}{ Liver } \\
\hline Fasn & $1.55 \pm 0.31$ & 0.1748 & $2.20 \pm 0.36^{*}$ & 0.0248 & $1.23 \pm 0.35$ & 0.5934 \\
\hline$G p \times 1$ & $0.89 \pm 0.12$ & 0.6197 & $1.54 \pm 0.15^{*}$ & 0.0127 & $1.31 \pm 0.14$ & 0.1653 \\
\hline Ppara & $1.10 \pm 0.16$ & 0.5427 & $1.41 \pm 0.11^{*}$ & 0.0478 & $0.98 \pm 0.10$ & 0.8582 \\
\hline $\operatorname{Slc} 2 a 2$ & $0.99 \pm 0.10$ & 0.9792 & $1.56 \pm 0.14^{*}$ & 0.0096 & $1.08 \pm 0.21$ & 0.7756 \\
\hline Srebp1c & $1.20 \pm 0.26$ & 0.4985 & $2.07 \pm 0.51$ & 0.0997 & $0.93 \pm 0.21$ & 0.8329 \\
\hline $\operatorname{Tnf}$ & $1.76 \pm 0.40$ & 0.2237 & $1.12 \pm 0.28$ & 0.7238 & $2.09 \pm 0.51$ & 0.0703 \\
\hline \multicolumn{7}{|c|}{ Bone marrow } \\
\hline Fasn & $0.94 \pm 0.05$ & 0.6811 & $0.94 \pm 0.07$ & 0.5619 & $1.20 \pm 0.15$ & 0.2388 \\
\hline$G p x 1$ & $0.56 \pm 0.08^{*}$ & 0.0053 & $1.45 \pm 0.13^{*}$ & 0.0228 & $1.05 \pm 0.18$ & 0.7983 \\
\hline Pparg & $1.35 \pm 0.39$ & 0.4349 & $0.78 \pm 0.10$ & 0.1829 & $1.21 \pm 0.18$ & 0.3279 \\
\hline
\end{tabular}

Mean fold regulation of genes involved in systemic metabolism and inflammation is presented for the animals on the high fat diet (45\% kcal from fat) relative to their control (AIN-93M). All target genes were normalized to invariant control $(P p i b)$. Symbol, $*$, represents a significant difference $(P=0.05)$ between dietary treatments within a given strain. 
study; however, early onset of hyperinsulinemia with HF diet was only observed in the C57BL/6N mice with an intact, functional Nnt. The coincident lower feed efficiency in the C57BL/6J compared to the C57BL/6N mice resulted in a delay in the development of hyperglycemia and shorter duration of exposure to conditions associated with impaired glucose tolerance.

The C57BL/6J and C57BL/6N mice had a markedly different hepatic response to the HF diet after $24 \mathrm{wk}$. Increased mRNA abundance of Fasn and a modest increase in Srebpc1 in the presence of severe liver steatosis in the C57BL/6N mice on the HF diet suggest an increase in hepatic triglyceride synthesis and storage. Conversely, the C57BL/6J substrain, which has lower glucokinase activity and thus impaired glucose sensing, may explain the lack of transcriptional regulation of Fasn and Srebplc [39]. Furthermore, C57BL/6N mice on the HF diet demonstrated an increase in Slc2a2 gene expression, which encodes the non-insulin-sensitive glucose transporter 2 and has been reported to be upregulated in response to a $\mathrm{HF}$ diet [42]. Histological evaluation suggests that the $\mathrm{C} 57 \mathrm{BL} / 6 \mathrm{~N}$ mice on the HF diet also experienced the most pronounced hepatic inflammation, compared to the C57BL/6J mice. Interestingly, the HF-induced NAFLD that develops in the C57BL/6J was previously attributed, in part, to the spontaneous mutation in the $N n t[39,43]$; however, the data demonstrate that the C57BL/6N mice, with a functional Nnt, develop more severe NAFLD in response to $\mathrm{HF}$ diet feeding. Given the more pronounced metabolic phenotype in the $\mathrm{C} 57 \mathrm{BL} / 6 \mathrm{~N}$ mice on the $\mathrm{HF}$ diet, it was counterintuitive that only the $\mathrm{C} 57 \mathrm{BL} / 6 \mathrm{~J}$ mice demonstrated the anticipated decrease in plasma adiponectin following a $\mathrm{HF}$ diet. Although the mechanism for reduced adiponectin during obesity and T2DM has been attributed, in part, to an increase in local TNF- $\alpha$ in adipose tissue [44], strainrelated variability of adiponectin gene expression and plasma has been previously documented [45]. As mice continue to be used for models of impaired glucose homeostasis, further investigation is warranted to fully understand these strain differences relative to metabolic handling. The findings of this study also demonstrate that the $\mathrm{C} 3 \mathrm{H} / \mathrm{HeJ}$ mice may not be completely resistant to diet-induced obesity and the subsequent metabolic changes. Differences in the $\mathrm{C} 3 \mathrm{H} / \mathrm{HeJ}$ strain's response to a high fat diet compared to previous reports may be attributed to the difference in the control strain used $[26,28]$. Specifically, previous studies have compared the $\mathrm{C} 3 \mathrm{H} / \mathrm{H} 3 \mathrm{~J}$ response to $\mathrm{HF}$ diet to $\mathrm{C} 3 \mathrm{H} / \mathrm{HeOuJ}$ or $\mathrm{C} 3 \mathrm{H} / \mathrm{HeN}$, both of which have a functional TLR-4 [26, 28]. However, in these studies, no comparisons were made with $\mathrm{C} 3 \mathrm{H} / \mathrm{HeJ}$ mice on a control diet. Therefore, it is not possible to determine if the differences in metabolic response to a HF diet are a result of TLR- 4 or genetic variability in the control substrain background. Furthermore, the $\mathrm{C} 3 \mathrm{H} / \mathrm{HeJ}$ strain has recently been shown to have a genetic variation in the leptin receptor gene (Lepr) [46]. This mutation could account for the impaired metabolic response observed in the $\mathrm{C} 3 \mathrm{H} / \mathrm{HeJ}$ strain on a $\mathrm{HF}$ diet due to the central role leptin has on regulating energy intake and expenditure. However, in the present study, food intake in the $\mathrm{C} 3 \mathrm{H} / \mathrm{HeJ}$ strain was not significantly altered and the absence of a leptin-mediated effect on food or energy intake does not rule out implications of the Lepr defect on the skeletal response [18, 19, 47].

In conjunction with the metabolic comparisons, the other primary objective of this study was to compare the skeletal response to a $\mathrm{HF}$ diet in two commonly used $\mathrm{C} 57 \mathrm{BL} / 6$ substrains. The C57BL/6J mice on the HF diet experienced a $13.6 \%$ reduction in trabecular bone of the vertebra, although not statistically significant. C57BL/6N was the only strain that exhibited significant trabecular bone loss which occurred only in the vertebra. In the absence of alterations in tibia trabecular and cortical bone microarchitecture, it is conceivable that the absence of alterations in the tibia could result from site-specific changes associated with increased adiposity and greater weight-bearing, which could offset some of the negative effects of glucose intolerance on bone $[48,49]$. Based on reports in the literature that bone biomechanical properties are changed in T2DM independent of alterations in bone mass $[8,50,51]$, the tibia was subjected to RPI testing. No detectable alterations in cortical bone strength were observed after 6 months in the absence of structural changes. The C57BL/6N mice had more prolonged exposure to hyperglycemia and hyperinsulinemia in response to the $\mathrm{HF}$ diet compared to the C57BL/6J substrain, and C57BL/6N were the only substrain to lose significant trabecular bone in the spine. While there have been conflicting reports on how a $\mathrm{HF}$ diet impacts bone in C57BL/6 mice [12,14-17], the results of this study indicate the skeletal response may be linked to the duration of disrupted insulin signaling and glucose intolerance. This idea is further supported by the response of the $\mathrm{C} 3 \mathrm{H} / \mathrm{HeJ}$ mice in which case an attenuated glucose, leptin, and insulin response to the HF diet failed to induce bone loss. Several reports have shown that a high fat diet uncouples bone turnover by increasing bone resorption and decreasing bone formation in various rodent models [16, 17, 21]. In this study, osteocalcin which is considered a marker of bone turnover was the only bone marker assessed and it was not altered at the end of the study. Although this does not rule out alterations in bone metabolism occurring earlier, future studies are needed to investigate the mechanism involved in the site-specific loss of bone observed in this animal model.

Based on recent literature describing the hormone OCN as a regulator of systemic energy metabolism [52-54], the role of $\mathrm{OCN}$ on both metabolic and skeletal changes induced by $\mathrm{HF}$ was investigated. After $24 \mathrm{wk}$, the $\mathrm{C} 57 \mathrm{BL} / 6 \mathrm{~N}$ mice on the HF diet had a lower ratio of plasma Glu-OCN/GlaOCN. Because circulating undercarboxylated (Glu-OCN) can act directly on pancreatic $\beta$-cells to stimulate insulin secretion [20,55-57], it would be expected that a reduction in Glu-OCN would lead to a decrease in insulin secretion. Instead, fasting plasma insulin was elevated in the $\mathrm{C} 57 \mathrm{BL} / 6 \mathrm{~N}$ mice on the HF diet compared to their respective controls. Alternatively, these results could indicate the direct effects impaired glucose tolerance has on osteoclastogenesis and bone resorption [58]. In this regard, the acidic milieu of the osteoclast-resorption lacunae is capable of decarboxylating $\mathrm{OCN}$, resulting in its release from the bone matrix and its subsequent circulation in the blood [55]. The complexity of OCN's role on bone and energy metabolism during glucose intolerance, as well as these implications in various mouse 
strains, warrants further investigation. Additional studies are also needed to determine how genes involved in the gamma carboxylation of OCN (i.e., Ggcx and Esp1) by osteoblasts as well as the role of decarboxylation of OCN by osteoclast are regulated in response to changes energy homeostasis $[55,59]$.

To date, this is the first study to directly compare the C57BL/6J and C57BL/6N substrains' response to a $\mathrm{HF}$ diet from a metabolic and skeletal perspective. Although neither substrain developed frank T2DM, the data presented here show that C57BL/6N mice exhibit an earlier metabolic response consistent with impaired glucose tolerance or prediabetes to the HF diet compared to the C57BL/6J mice. Moreover, the skeletal response followed that of the metabolic changes; this was demonstrated by the fact that significant trabecular bone loss occurred in the C57BL/6N mice, which demonstrated the robust metabolic alterations associated with clinical T2DM. Given the observed differences in feed efficiency between the C57BL/6 substrains, further research is also warranted to identify the mechanisms underlying altered energy utilization. In contrast to the C57BL/ 6 mice, the $\mathrm{C} 3 \mathrm{H} / \mathrm{HeJ}$ strain was protected from the metabolic and skeletal changes induced by a HF diet. While a number of questions remain including how bone metabolism is being altered in response to a high fat diet on a molecular level, this study highlights the need to consider not only the most appropriate strain but also the most appropriate substrain of mouse when designing experiments. Other important factors to consider when studying the relationship between glucose intolerance and bone include the site-specific skeletal response and the study duration. These decisions could significantly impact data interpretation and the translational implications as they relate to understanding how bone metabolism is altered in the context of T2DM.

\section{Conflict of Interests}

The authors declare that there is no conflict of interests regarding the publication of this paper.

\section{Acknowledgments}

The authors would like to express their gratitude to Kristen Hester and Sandra Peterson (Department of Nutritional Sciences, Oklahoma State University, Stillwater, OK 74078) for their technical assistance. This work was generously supported by Oklahoma Center for the Advancement of Science and Technology (HR10-068); Oklahoma Agriculture Experiment Station (OKL02867); and United States Department of Agriculture (2012-67011-19906).

\section{References}

[1] U. Rishaug, K. I. Birkeland, J. A. Falch, and S. Vaaler, "Bone mass in non-insulin-dependent diabetes mellitus," Scandinavian Journal of Clinical and Laboratory Investigation, vol. 55, no. 3, pp. 257-262, 1995.

[2] P. L. A. van Daele, R. P. Stolk, H. Burger et al., "Bone density in non-insulin-dependent diabetes mellitus: the Rotterdam study," Annals of Internal Medicine, vol. 122, no. 6, pp. 409-414, 1995.
[3] R. P. Stolk, P. L. A. van Daele, H. A. P. Pols et al., "Hyperinsulinemia and bone mineral density in an elderly population: the Rotterdam study," Bone, vol. 18, no. 6, pp. 545-549, 1996.

[4] K. K. Nicodemus and A. R. Folsom, "Type 1 and type 2 diabetes and incident hip fractures in postmenopausal women," Diabetes Care, vol. 24, no. 7, pp. 1192-1197, 2001.

[5] L. J. Melton III, C. L. Leibson, S. J. Achenbach, T. M. Therneau, and S. Khosla, "Fracture risk in type 2 diabetes: update of a population-based study," Journal of Bone and Mineral Research, vol. 23, no. 8, pp. 1334-1342, 2008.

[6] A. V. Schwartz, D. E. Sellmeyer, K. E. Ensrud et al., "Older women with diabetes have an increased risk of fracture: a prospective study," Journal of Clinical Endocrinology and Metabolism, vol. 86, no. 1, pp. 32-38, 2001.

[7] M. Janghorbani, D. Feskanich, W. C. Willett, and F. Hu, "Prospective study of diabetes and risk of hip fracture: the nurses' health study," Diabetes Care, vol. 29, no. 7, pp. 1573-1578, 2006.

[8] A. V. Schwartz, E. Vittinghoff, D. C. Bauer et al., "Association of BMD and FRAX score with risk of fracture in older adults with type 2 diabetes," Journal of the American Medical Association, vol. 305, no. 21, pp. 2184-2192, 2011.

[9] R. J. Fajardo, L. Karim, V. I. Calley, and M. L. Bouxsein, "A review of rodent models of type 2 diabetic skeletal fragility," Journal of Bone and Mineral Research, vol. 29, no. 5, pp. 10251040, 2014.

[10] R. S. Surwit, C. M. Kuhn, C. Cochrane, J. A. McCubbin, and M. N. Feinglos, "Diet-induced type II diabetes in C57BL/6J mice," Diabetes, vol. 37, no. 9, pp. 1163-1167, 1988.

[11] S. Collins, T. L. Martin, R. S. Surwit, and J. Robidoux, "Genetic vulnerability to diet-induced obesity in the C57BL/6J mouse: physiological and molecular characteristics," Physiology \& Behavior, vol. 81, no. 2, pp. 243-248, 2004.

[12] C. Gallou-Kabani, A. Vigé, M.-S. Gross et al., "C57BL/6J and $\mathrm{A} / \mathrm{J}$ mice fed a high-fat diet delineate components of metabolic syndrome," Obesity, vol. 15, no. 8, pp. 1996-2005, 2007.

[13] J. J. Cao, B. R. Gregoire, and H. Gao, "High-fat diet decreases cancellous bone mass but has no effect on cortical bone mass in the tibia in mice," Bone, vol. 44, no. 6, pp. 1097-1104, 2009.

[14] J. M. Patsch, F. W. Kiefer, P. Varga et al., "Increased bone resorption and impaired bone microarchitecture in shortterm and extended high-fat diet-induced obesity," Metabolism: Clinical and Experimental, vol. 60, no. 2, pp. 243-249, 2011.

[15] S. S. Ionova-Martin, J. M. Wade, S. Tang et al., "Changes in cortical bone response to high-fat diet from adolescence to adulthood in mice," Osteoporosis International, vol. 22, no. 8, pp. 2283-2293, 2011.

[16] F. Parhami, Y. Tintut, W. G. Beamer, N. Gharavi, W. Goodman, and L. L. Demer, "Atherogenic high-fat diet reduces bone mineralization in mice," Journal of Bone and Mineral Research, vol. 16, no. 1, pp. 182-188, 2001.

[17] G. V. Halade, M. M. Rahman, P. J. Williams, and G. Fernandes, "High fat diet-induced animal model of age-associated obesity and osteoporosis," The Journal of Nutritional Biochemistry, vol. 21, no. 12, pp. 1162-1169, 2010.

[18] C. M. Steppan, D. T. Crawford, K. L. Chidsey-Frink, H. Ke, and A. G. Swick, "Leptin is a potent stimulator of bone growth in ob/ob mice," Regulatory Peptides, vol. 92, no. 1-3, pp. 73-78, 2000.

[19] P. Ducy, M. Amling, S. Takeda et al., "Leptin inhibits bone formation through a hypothalamic relay: a central control of bone mass," Cell, vol. 100, no. 2, pp. 197-207, 2000. 
[20] N. K. Lee, H. Sowa, E. Hinoi et al., "Endocrine regulation of energy metabolism by the skeleton," Cell, vol. 130, no. 3, pp. 456469, 2007.

[21] X. M. Lu, H. Zhao, and E. H. Wang, "A high-fat diet induces obesity and impairs bone acquisition in young male mice," Molecular Medicine Reports, vol. 7, no. 4, pp. 1203-1208, 2013.

[22] K. Mekada, K. Abe, A. Murakami et al., "Genetic differences among C57BL/6 substrains," Experimental Animals, vol. 58, no. 2, pp. 141-149, 2009.

[23] H. C. Freeman, A. Hugill, N. T. Dear, F. M. Ashcroft, and R. D. Cox, "Deletion of nicotinamide nucleotide transhydrogenase: a new quantitive trait locus accounting for glucose intolerance in C57BL/6J mice," Diabetes, vol. 55, no. 7, pp. 2153-2156, 2006.

[24] T.-T. Huang, M. Naeemuddin, S. Elchuri et al., "Genetic modifiers of the phenotype of mice deficient in mitochondrial superoxide dismutase," Human Molecular Genetics, vol. 15, no. 7, pp. 1187-1194, 2006.

[25] B. Ahrén and G. Pacini, "Insufficient islet compensation to insulin resistance vs. reduced glucose effectiveness in glucoseintolerant mice," American Journal of Physiology: Endocrinology and Metabolism, vol. 283, no. 4, pp. E738-E744, 2002.

[26] M. Poggi, D. Bastelica, P. Gual et al., "C $3 \mathrm{H} / \mathrm{HeJ}$ mice carrying a toll-like receptor 4 mutation are protected against the development of insulin resistance in white adipose tissue in response to a high-fat diet," Diabetologia, vol. 50, no. 6, pp. 1267-1276, 2007.

[27] D. M. L. Tsukumo, M. A. Carvalho-Filho, J. B. C. Carvalheira et al., "Loss-of-function mutation in toll-like receptor 4 prevents diet-induced obesity and insulin resistance," Diabetes, vol. 56, no. 8, pp. 1986-1998, 2007.

[28] H. Nakamura, Y. Fukusaki, A. Yoshimura et al., "Lack of Toll-like receptor 4 decreases lipopolysaccharide-induced bone resorption in $\mathrm{C} 3 \mathrm{H} / \mathrm{HeJ}$ mice in vivo," Oral Microbiology and Immunology, vol. 23, no. 3, pp. 190-195, 2008.

[29] M. Rauner, W. Sipos, and P. Pietschmann, "Osteoimmunology," International Archives of Allergy and Immunology, vol. 143, no. 1, pp. 31-48, 2007.

[30] K. Bandow, A. Maeda, K. Kakimoto et al., "Molecular mechanisms of the inhibitory effect of lipopolysaccharide (LPS) on osteoblast differentiation," Biochemical and Biophysical Research Communications, vol. 402, no. 4, pp. 755-761, 2010.

[31] K. Gunaratnam, C. Vidal, R. Boadle, C. Thekkedam, and G. Duque, "Mechanisms of palmitate-induced cell death in human osteoblasts," Biology Open, vol. 2, no. 12, pp. 1382-1389, 2013.

[32] E. A. Droke, K. A. Hager, M. R. Lerner et al., "Soy isoflavones avert chronic inflammation-induced bone loss and vascular disease," Journal of Inflammation, vol. 4, article 17, 2007.

[33] M. R. Hill, K. D. Denson, S. Y. Bu et al., "LPS-mediated chronic inflammation increases circulating RANKL coincident with bone loss in C57BL/6 mice," Journal of Bone and Mineral Research, abstract S410, 2006.

[34] S.-R. Oh, O.-J. Sul, Y.-Y. Kim et al., "Saturated fatty acids enhance osteoclast survival," Journal of Lipid Research, vol. 51, no. 5, pp. 892-899, 2010.

[35] R. S. Surwit, M. N. Feinglos, J. Rodin et al., "Differential effects of fat and sucrose on the development of obesity and diabetes in C57BL/6J and A/J mice," Metabolism, vol. 44, no. 5, pp. 645-651, 1995.

[36] E. Rendina, Y. F. Lim, D. Marlow et al., "Dietary supplementation with dried plum prevents ovariectomy-induced bone loss while modulating the immune response in C57BL/6J mice," Journal of Nutritional Biochemistry, vol. 23, no. 1, pp. 60-68, 2012.
[37] E. Rendina, K. D. Hembree, M. R. Davis et al., “Dried plum's unique capacity to reverse bone loss and alter bone metabolism in postmenopausal osteoporosis model," PLOS ONE, vol. 8, no. 3, Article ID e60569, 2013.

[38] K. L. Svenson, R. von Smith, P. A. Magnani et al., "Multiple trait measurements in 43 inbred mouse strains capture the phenotypic diversity characteristic of human populations," Journal of Applied Physiology, vol. 102, no. 6, pp. 2369-2378, 2007.

[39] A. A. Toye, J. D. Lippiat, P. Proks et al., "A genetic and physiological study of impaired glucose homeostasis control in C57BL/6J mice," Diabetologia, vol. 48, no. 4, pp. 675-686, 2005.

[40] A. Nicholson, P. C. Reifsnyder, R. D. Malcolm et al., "Dietinduced obesity in two C57BL/6 substrains with intact or mutant nicotinamide nucleotide transhydrogenase (Nnt) gene," Obesity, vol. 18, no. 10, pp. 1902-1905, 2010.

[41] H. Freeman, K. Shimomura, E. Horner, R. D. Cox, and F. M. Ashcroft, "Nicotinamide nucleotide transhydrogenase: a key role in insulin secretion," Cell Metabolism, vol. 3, no. 1, pp. 3545, 2006.

[42] E. Riu, T. Ferre, A. Hidalgo et al., "Overexpression of c-myc in the liver prevents obesity and insulin resistance," The FASEB Journal, vol. 17, no. 12, pp. 1715-1717, 2003.

[43] Q. M. Anstee and R. D. Goldin, "Mouse models in non-alcoholic fatty liver disease and steatohepatitis research," International Journal of Experimental Pathology, vol. 87, no. 1, pp. 1-16, 2006.

[44] G. R. Hajer, T. W. van Haeften, and F. L. J. Visseren, "Adipose tissue dysfunction in obesity, diabetes, and vascular diseases," European Heart Journal, vol. 29, no. 24, pp. 2959-2971, 2008.

[45] M. Haluzik, C. Colombo, O. Gavrilova et al., "Genetic background (C57BL/6J Versus FVB/N) strongly influences the severity of diabetes and insulin resistance in ob/ob mice," Endocrinology, vol. 145, no. 7, pp. 3258-3264, 2004.

[46] S. Kapur, M. Amoui, C. Kesavan et al., "Leptin receptor (Lepr) is a negative modulator of bone mechanosensitivity and genetic variations in Lepr may contribute to the differential osteogenic response to mechanical stimulation in the C57BL/6J and $\mathrm{C} 3 \mathrm{H} / \mathrm{HeJ}$ pair of mouse strains," The Journal of Biological Chemistry, vol. 285, no. 48, pp. 37607-37618, 2010.

[47] A. Hamann and S. Matthaei, "Regulation of energy balance by leptin," Experimental and Clinical Endocrinology \& Diabetes, vol. 104, no. 4, pp. 293-300, 1996.

[48] A. C. Looker, K. M. Flegal, and L. J. Melton III, "Impact of increased overweight on the projected prevalence of osteoporosis in older women," Osteoporosis International, vol. 18, no. 3, pp. 307-313, 2007.

[49] S. J. Kuruvilla, S. D. Fox, D. M. Cullen, and M. P. Akhter, "Site specific bone adaptation response to mechanical loading," Journal of Musculoskeletal Neuronal Interactions, vol. 8, no. 1, pp. 71-78, 2008.

[50] T. Yamaguchi, I. Kanazawa, M. Yamamoto et al., "Associations between components of the metabolic syndrome versus bone mineral density and vertebral fractures in patients with type 2 diabetes," Bone, vol. 45, no. 2, pp. 174-179, 2009.

[51] J. N. Farr, M. T. Drake, S. Amin, L. J. Melton III, L. K. McCready, and S. Khosla, "In vivo assessment of bone quality in postmenopausal women with type 2 diabetes," Journal of Bone and Mineral Research, vol. 29, no. 4, pp. 787-795, 2014.

[52] T. L. Clemens and G. Karsenty, "The osteoblast: an insulin target cell controlling glucose homeostasis," Journal of Bone and Mineral Research, vol. 26, no. 4, pp. 677-680, 2011. 
[53] M. Ferron, E. Hinoi, G. Karsenty, and P. Ducy, "Osteocalcin differentially regulates $\beta$ cell and adipocyte gene expression and affects the development of metabolic diseases in wild-type mice," Proceedings of the National Academy of Sciences of the United States of America, vol. 105, no. 13, pp. 5266-5270, 2008.

[54] E. Hinoi, N. Gao, D. Y. Jung et al., "An osteoblast-dependent mechanism contributes to the leptin regulation of insulin secretion," Annals of the New York Academy of Sciences, vol. 1173, supplement 1, pp. E20-E30, 2009.

[55] M. Ferron, J. Wei, T. Yoshizawa et al., "Insulin signaling in osteoblasts integrates bone remodeling and energy metabolism," Cell, vol. 142, no. 2, pp. 296-308, 2010.

[56] M. Ferron, M. D. McKee, R. L. Levine, P. Ducy, and G. Karsenty, "Intermittent injections of osteocalcin improve glucose metabolism and prevent type 2 diabetes in mice," Bone, vol. 50, no. 2, pp. 568-575, 2012.

[57] M.-T. Rached, A. Kode, B. C. Silva et al., "FoxO1 expression in osteoblasts regulates glucose homeostasis through regulation of osteocalcin in mice," Journal of Clinical Investigation, vol. 120, no. 1, pp. 357-368, 2010.

[58] K. I. Larsen, M. Falany, W. Wang, and J. P. Williams, “Glucose is a key metabolic regulator of osteoclasts; glucose stimulated increases in ATP/ADP ratio and calmodulin kinase II activity," Biochemistry and Cell Biology, vol. 83, no. 5, pp. 667-673, 2005.

[59] M. Haraikawa, N. Tsugawa, N. Sogabe et al., "Effects of gammaglutamyl carboxylase gene polymorphism (R325Q) on the association between dietary vitamin $\mathrm{K}$ intake and gammacarboxylation of osteocalcin in young adults," Asia Pacific Journal of Clinical Nutrition, vol. 22, no. 4, pp. 646-654, 2013. 


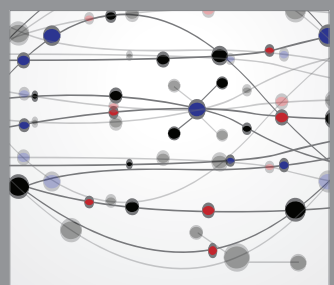

The Scientific World Journal
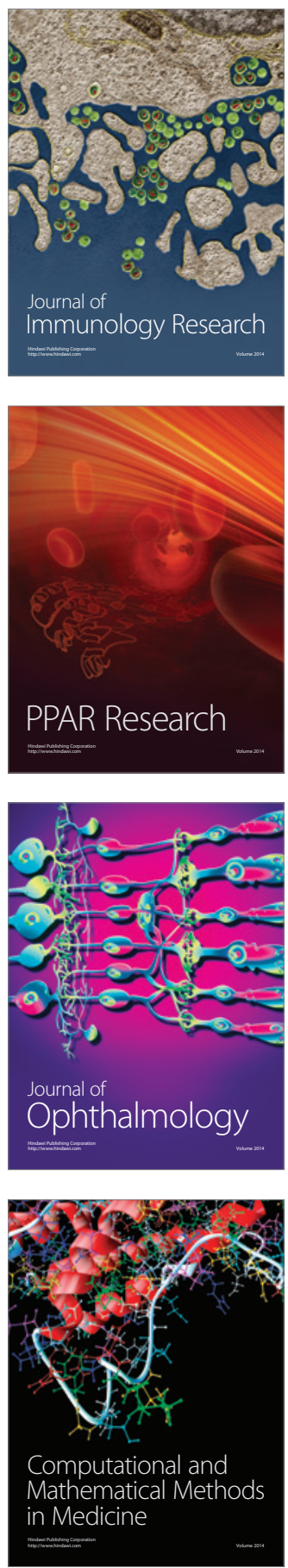

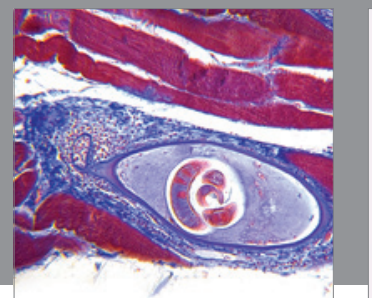

Gastroenterology

Research and Practice
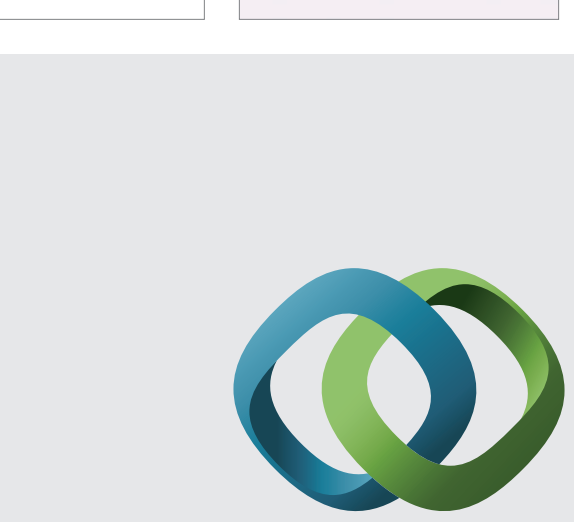

\section{Hindawi}

Submit your manuscripts at

http://www.hindawi.com
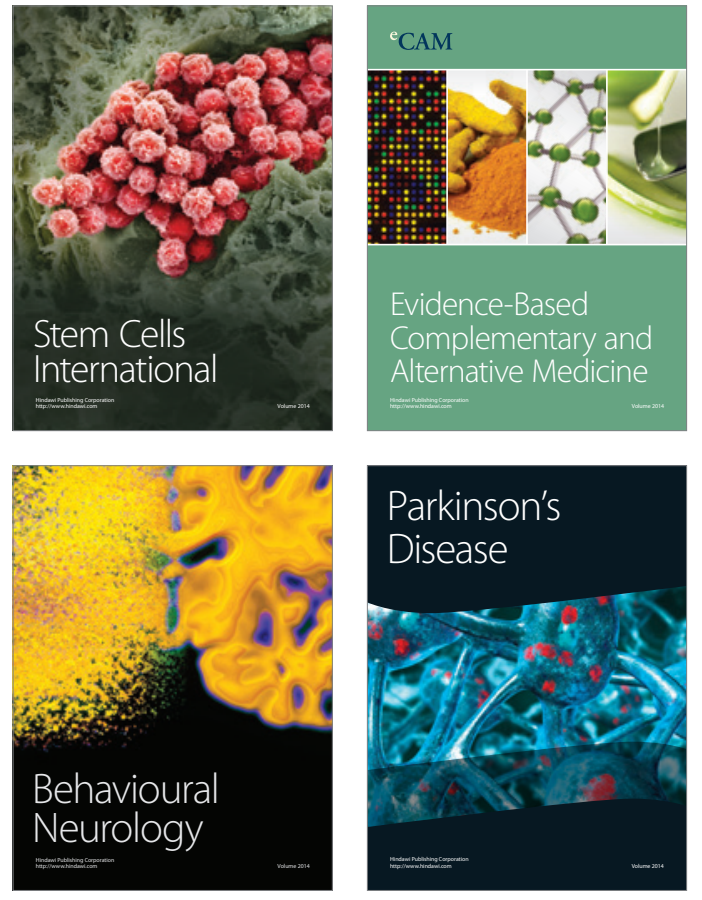
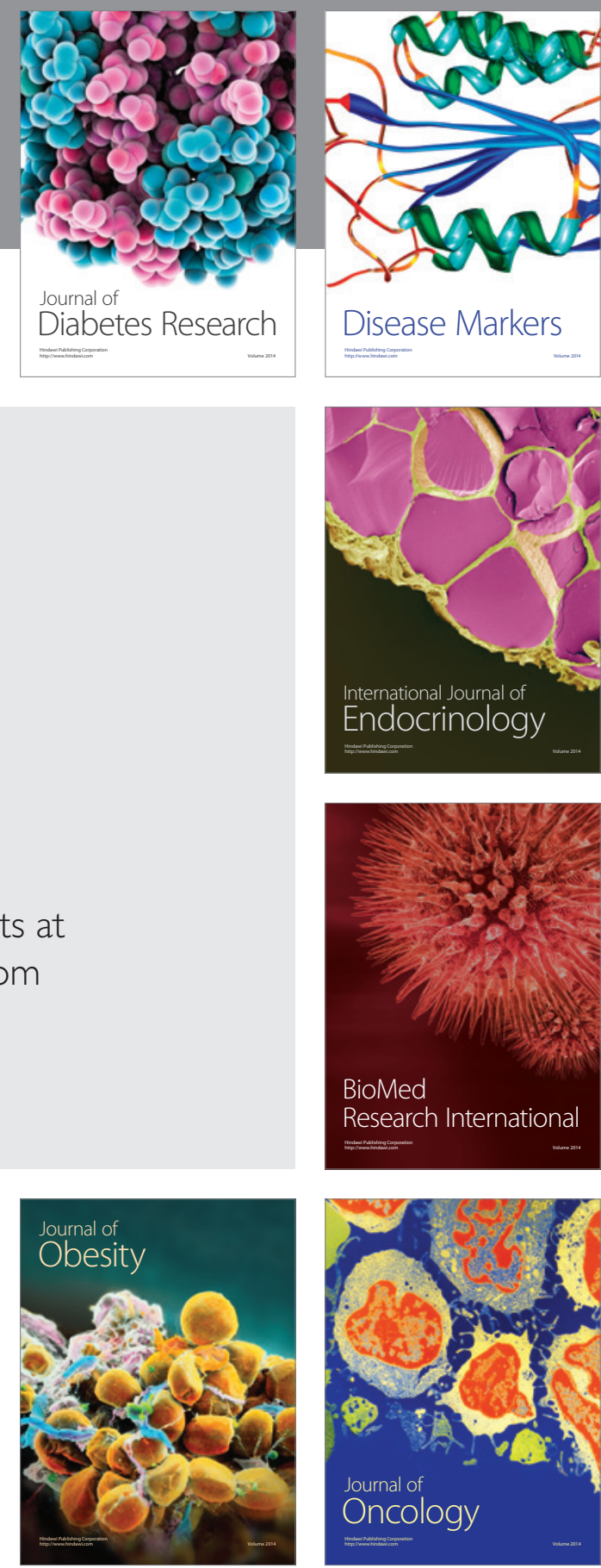

Disease Markers
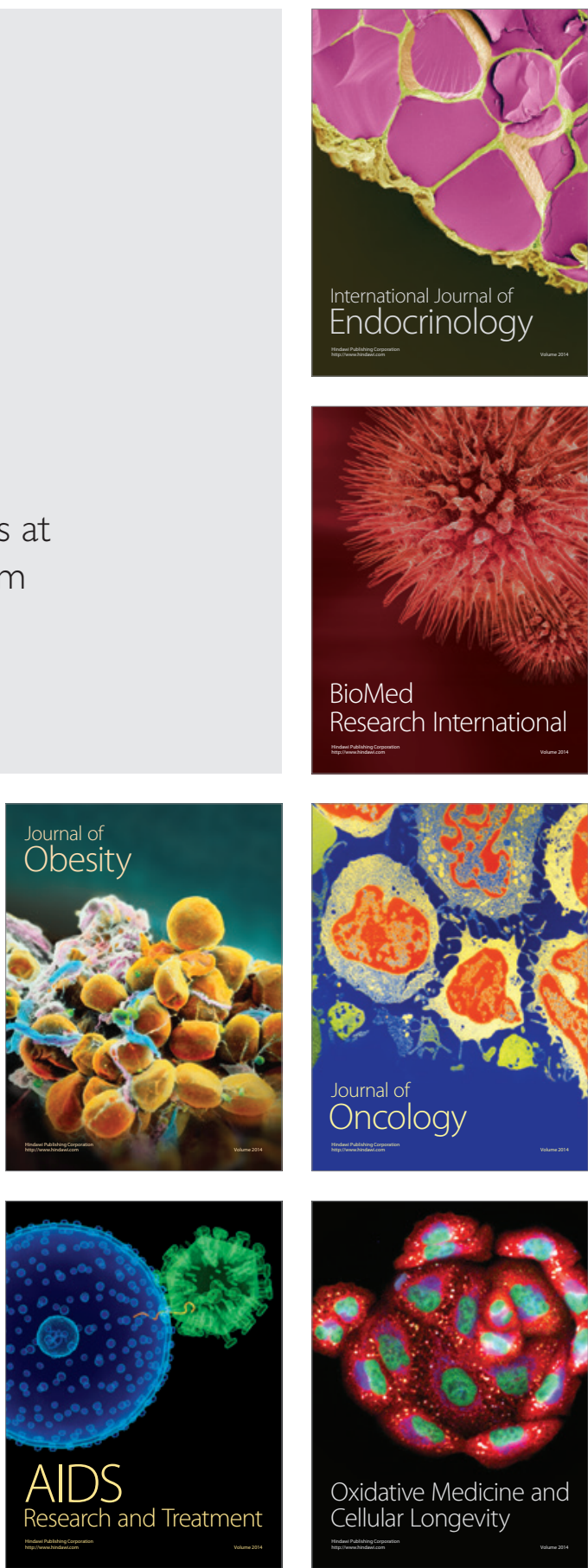